\title{
Dysembryoplastic Neuroepithelial Tumor
}

National Cancer Institute

\section{Source}

National Cancer Institute. Dysembryoplastic Neuroepithelial Tumor. NCI Thesaurus.

Code C9505.

A benign glial-neuronal neoplasm. It is usually supratentorial, located, generally, in the cortex and occurs in children and young adults with a long-standing history of partial seizures. A histologic hallmark of this tumor is the 'specific glioneuronal element', characterized by columns, made up of bundles of axons, oriented perpendicularly to the cortical surface. (Adapted from WHO) 